\title{
Growing pains
}

\section{Current economic conditions are putting a strain on the nascent world of proteomics. But many companies are managing to flourish by carving out their own market niche. Kendall Powell investigates.}

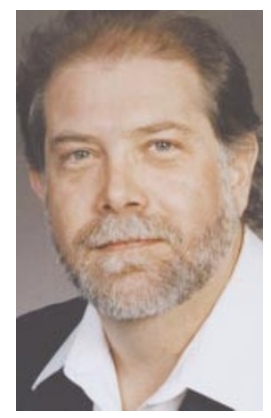

Lawrence Cohen sees the in-depth study of proteins as unavoidable.

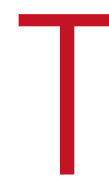

he economy has been tough on proteomics companies. In the wake of the publication of the draft sequence of the human genome, anything to do with the logical next step studying protein expression in cells and tissues - looked hot. Companies sprang up to provide technology and protein data to paying customers. And existing firms launched proteomics divisions in the hope that protein data would usher in a new era of drug discovery.

Those expectations have now come down to Earth with a bump, with many small firms either closing shop or scaling back, and several large companies paring down their proteomics divisions. But proteomics is not out of the picture. Companies of all sizes that provide goods and services making direct contributions to drug discovery seem poised to thrive, offering jobs to protein scientists who also have skills in computer science or engineering.

There is a group of companies developing proteinsurvey technology that is shifting from development to applications and broadening out, says Lawrence Cohen, president and chief executive of Zyomyx, a biotechnology company based in Hayward, California. His firm produced one of the first commercially available protein-array chips, which allows users to test biological samples for a range of proteins from the human immune system. "Proteomics has weathered the storm of the economy because the direct study of proteins is inevitable and imperative to research," he says.

It is also key to drug discovery, where it will aid the search for valid drug targets and biomarkers for the early detection of disease, as well as help to chart disease-related pathways and protein interactions. As a result, many proteomics companies are starting to explore drug-discovery avenues, with smaller firms gearing themselves up to provide niche services to the larger pharmaceutical companies. In general, what the big drug firms want are proteomics data that fit their suite of drug targets or disease areas, as these could reduce the time spent hunting for active - and safe -

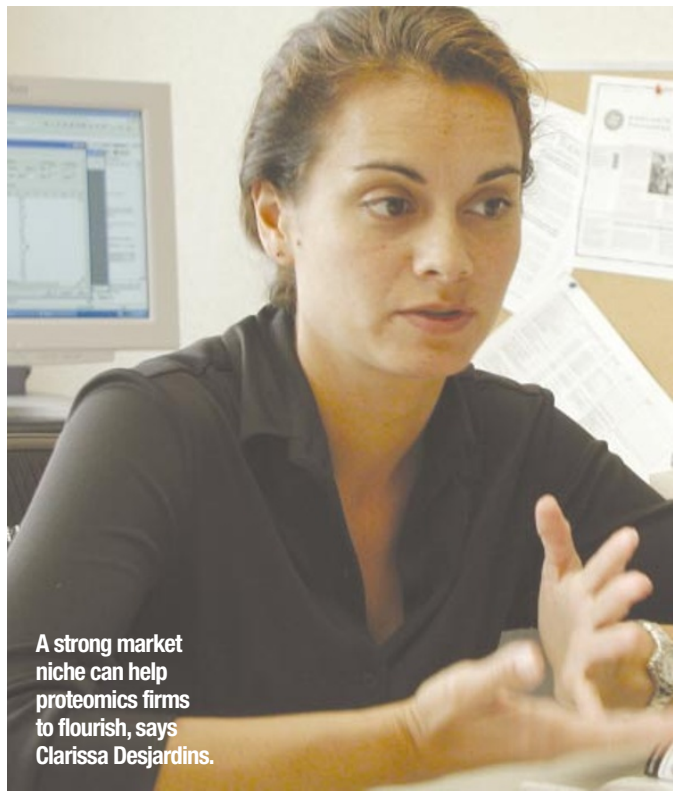

lead compounds (see 'Tight focus', opposite).

Companies that have carved themselves a niche that appeals to pharmaceutical partners have managed to ride out the economic downturn, says Clarissa Desjardins, founder and an executive vice-president of Caprion Pharmaceuticals in Montreal, Canada. But the key now is to continue to develop that niche. Caprion's technology probes the proteomes of specific cellular compartments or membranes. Although it is now a reasonably mature technology, the development phase is not necessarily over, Desjardins says. "We want creative people from this field to continue to improve on it so that our partners have more options," she explains. Caprion also has a growing need for people with scientific backgrounds who can cover business development, law and technology surveillance.

\section{VARIETY SHOW}

Cellzome, based in Britain and Germany, also places an emphasis on diversity and teamwork. The company was originally spun off from the European Molecular Biology Laboratory in Heidelberg, Germany. "We liked the international atmosphere there, so we transferred it to Cellzome," says Gitte Neubauer, co-founder of the company.

Drug development at the firm involves trawling through the human proteome for proteins that bind known drugs or drug candidates. During the next two years, Cellzome plans to add a medicinal chemistry and pharmacology department of about 40 people to bolster its efforts. Neubauer says that initially the firm will hire senior people with industry-level experience, followed by a second round of fresh PhDs or postdocs.

The explosion of interest in proteomics has kept companies that specialize in mass spectrometry and protein separation on their toes. As universities and research institutes add proteomics facilities and encourage exploration in the field, lab-supply companies are adjusting their product lines accordingly.

One such company, Invitrogen in Carlsbad, California, is seeking creative people who can devise 


\section{Tight focus}

When Hanjo Lim
finished his postdoc at
the Scripps Research
Institute in La Jolla,
California, two-and a-
half years ago, he found
himself in demand.
Coming out of one of
the country's premier
proteomics labs, Lim had
four job offers, two at
biotechnology companies
and two at major
pharmaceutical firms.
He chose Aventis
Pharmaceuticals, where
he joined as a senior
scientist in its proteomics
group at Bridgewater,

New Jersey. At the time, biotech and especially proteomics companies were "just not stable" compared with drug firms, he says.

The proteomics group, which focuses on the central nervous system and inflammatory diseases, was just getting started and Lim jumped at the chance to contribute to building a team of mass spectrometry specialists.

"I was interested in drug discovery rather than the academic field, and if I joined a new group, I could influence its direction," he says.

Seeing the whole drug-discovery process has taught Lim about bioinformatic and genomic approaches as well. But he notes that there are disadvantages to working in such a product-driven environment. There is no room for technology development, for example, something that Lim hoped he would have time for.

Even so, there is plenty to keep a highly trained proteome scientist occupied. Lim says that as projects broaden out, his group is moving into mapping protein pathways and finding biomarkers for diagnosing disease. And group members are key advisers to the company on how to outsource proteomic projects. "Proteomics approaches are growing towards more complex systems and are now heavily involved with pathway biology," Lim says. "Coming up with a good experimental plan is not easy."

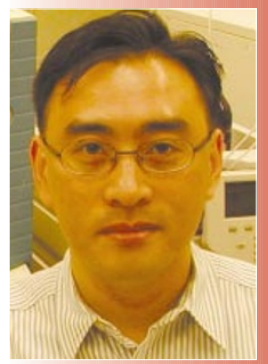

Hanjo Lim feels that his spell in industry has been rewarding. new ways of doing something faster, easier or cheaper. "We look for people with solid chemistry or biochemistry training," says Jay Amshey, a vicepresident at the company. "If they know why and how something works, then they know enough to make it better." Invitrogen has seen its sales grow over the past two years, and is now hiring PhD-level scientists for all aspects of its business, including manufacturing, sales, business development and law.

\section{CRITICAL MASS}

Applied Biosystems in Foster City, California, is focusing strongly on its mass-spectrometry systems, which are designed with the proteome in mind. "Without question, this is a growth area for us," says David Hicks, the firm's marketing director for proteomics. "But we also want to deliver entirely new workflows for applications and for that we need all the classic talent you would anticipate." That means electrical and mechanical engineers, ion physicists and software developers. Once these systems are developed, the firm needs biochemists and bioinformaticians to test the new products, and scientists to train customers and develop new applications in the field.

Such a broad spread of talent is becoming important for the company to meet the needs of an increasingly diverse range of customers. "Real people skills" are needed to encourage adoption of new technology, Hicks says. Companies often find that cell biologists and clinical researchers using mass spectrometry in proteomics for the first time need extra encouragement and training.

Another company that wants to put a mass spectrometer on every lab bench is also investing in customer care. Ciphergen

Flexibility and variety are important in protein research, according to Gitte Neubauer.

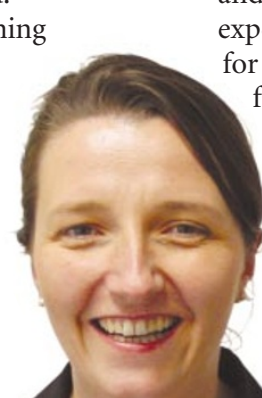

in Fremont, California, has about 50 research scientists around the world who are dedicated to helping clients understand and set up the company's ProteinChip system, which combines protein separation on a chip with time-of-flight mass spectrometry. Ciphergen tends to hire postdocs with training in protein biochemistry for these posts.

Zyomyx also produces a protein chip, which features a number of cell-signalling molecules for testing against a tiny amount of sample fluid. But with the chip and reader system complete, the technology is reasonably mature, says Cohen, so the company is currently seeking people for sales, marketing and technology-support roles.

Cohen believes that the future for protein arrays will see far greater miniaturization and an increased ability to do many experiments in parallel on the same chip. Designing these new arrays, with active proteins tethered to a surface, will require expertise encompassing silicon microfabrication, nanotechnology, microfluidics and detection physics.

The next wave of technology will need to be able to wade through more complex protein mixtures, decipher how many proteins can result from one gene, and tackle 'personalized' molecular medicine. Many experts are predicting that mass spectrometry will do for proteins what the polymerase chain reaction did

for DNA, eventually offering rapid protein

identification at the bench. But to get there, the developers and promoters of such technical advances had better bulk up their protein knowledge base now. "After the whole genomics revolution, there were lots of gene jockeys and protein chemistry was out of fashion," says Desjardins. "But now it's back and has become a key skill." For those with a combination of protein knowledge, creativity and the technical skills to make meaningful patterns leap out of the proteome, industry offers a bright future. Kendall Powell is a science writer in Broomfield, Colorado. 